\title{
THE RESEARCH ON CHARACTERISTIC PARAMETERS AND RESISTANCE CHART OF OPERATION AND MAINTENANCE TRIMARAN IN THE SEA
}

\author{
Yue Chen \\ Lingyu Yang \\ Yi Xie \\ Song Yu \\ School of Naval Architecture and Ocean Engineering, Jiangsu University of Science and Technology, \\ Zhenjiang, China
}

\begin{abstract}
The paper determined the volume ratio of the main hull and side hull and their position characteristic parameter of operation and maintenance trimaran. Numerical simulation technology was used to do the analysis and calculation of trimarans which have different volume ratio of the main and side hull, and on this basis, the paper tried different positions of main and side hull, finally got the trimaran with optimum resistance performance and the chart of trimaran resistance estimation, so as to provide a new way in the selection of feature parameter of offshore wind farm maintenance trimaran and its resistance estimation.
\end{abstract}

Keywords: wind power maintenance; trimaran; characteristic parameter; CFD; resistance charts

\section{INTRODUCTION}

The problem of the daily maintenance of wind turbines begins to emerge with the rapid growth of offshore wind farms. Operation and maintenance ships are indispensable vehicles in offshore wind farms, their performance directly affect the maintenance of wind turbines.

Offshore wind farms mostly use small monomer or catamaran hull. Small mono-hull ship cannot meet the requirements of operation and maintenance when the wind and waves are large. Catamarans have larger deck area than mono-hull ships and their stability have also been greatly improved, but catamarans are more likely to twist shake and anxious shake. Trimarans have better seakeeping performance and are faster than mono hull ships and catamarans. And their safety performance have also been improved to some extent, so trimarans drew more and more attention in the operation and maintenance of wind power.

At present, slender, ultra high speed trimarans are always researched for military use, and mainly in the following aspects ${ }^{[1]}$ : (1)the determination of molded lines of main and side hull of trimarans ; (2) relative position of main hull and side hull: through theoretical and experimental research method to determine the reasonable arrangement of the side hull, and studying the impact of the side hull position, symmetry, drainage volume and the difference of angle of attack on wave making resistance; (3) the numerical resistance prediction: including the model test, theoretical calculation and numerical simulation; (4) researches on the manipulation of trimarans. At present, it is rare to study the 
effect of side hull volume displacement on the performance of high speed trimarans ${ }^{[2]}$. In addition, the numerical simulation or experimental methods are widely used in the estimation of the resistance of trimarans, and there are some difficulties in the estimation of the resistance of the high speed trimarans. This paper try to get the high speed trimarans resistance estimation chart by exploring the resistance performance of high speed trimarans, the displacement of the main and side hull and relative position, providing certain reference and help for estimating the trimaran characteristic parameters and resistance for the design.

\section{THE DETERMINATION OF THE CHARACTERISTIC PARAMETERS OF THE TRIMARAN}

\section{MAIN FACTORS}

\section{MAIN BODY ELEMENT}

The main elements of operation and maintenance trimaran, as shown in table 1:

Tab. 1 elements of the main body

\begin{tabular}{c|c|c}
\hline Elements & Main hull & Side hull \\
\hline Waterline length $(\mathrm{m})$ & 20 & 7.5 \\
\hline Modeled breadth $(\mathrm{m})$ & 4 & 1.5 \\
\hline Water breadth $(\mathrm{m})$ & 3.8 & 1.2 \\
\hline Modeled depth $(\mathrm{m})$ & 2.5 & 2 \\
\hline Draught $(\mathrm{m})$ & 1.2 & 0.7 \\
\hline Block coefficient & 0.41 & 0.41 \\
\hline Displacement $(\mathrm{t})$ & 38.7 & 2.6 \\
\hline
\end{tabular}

\section{RELATIVE POSITION RELATION OF MAIN HULL AND SIDE HULL}

The relative position of the main hull is expressed by the transverse space $b$ and the longitudinal space 1 , as shown in figure 1 . The effect due to the difference of side hull position on the resistance and seakeeping performance is more obvious, different locations may produce great influence on the performance of trimaran ${ }^{[3]}$.

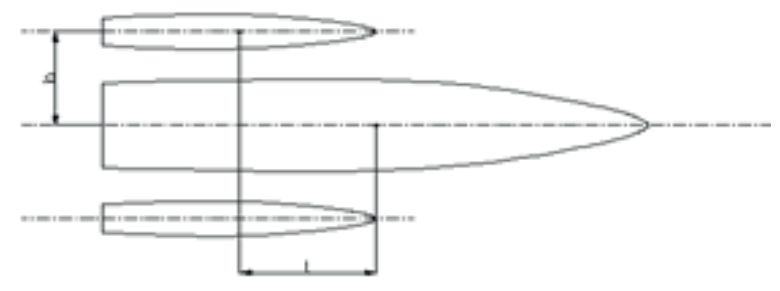

Fig. 1 the relative position of main hull and side hull

For basic ship types, the stern transom plate of side hulls are flush with the stern transom plate of main hull, transverse space $b$ is $101.25 \%$ of $B, 4.05 \mathrm{~m}$.

\section{HULL MODEL}

According to the scales, round bilges are adopt as the line shape of the cross section of the trimaran main and side hull, side hulls are symmetrically arranged on two sides of the main body, NAPA was used to design the line type of the hulls, a built model as shown in Figure 2:

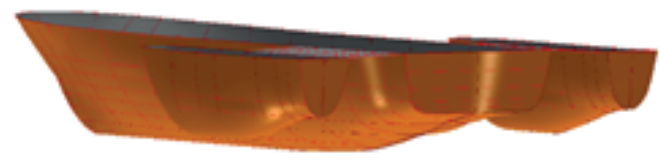

Fig. 2 Trimaran model

\section{CHARACTERISTIC PARAMETERS}

Two characteristic parameters: the proportion of the displacement of the side body and the relative position of the main body, are studied in this paper.

\section{SIDE HULL DISPLACEMENT PROPORTION OF TOTAL DRAINAGE VOLUME}

For trimarans, the main hulls are all slender, the displacement of one side hull is usually blow $10 \%$ of the total displacement ${ }^{[4][5]}$. Wind farm maintenance mainly includes the maintenance of personnel transport and landing or leaving wind power towers, requires fast and efficient ship. Because of the bad weather in wind farm, good stability, rapidity and good seakeeping performance are required for the ship of operation and maintenance. Thus the displacement of side hull is bigger than ultrahigh speed trimaran. The proportion of the displacement of the base ship type is $12 \%$. Considering the needs for the research on the performance of the operation and maintenance ships, this paper determines the other three sets: $9 \%, 15 \%$ and $18 \%$, respectively.

\section{THE PARAMETER OF MAIN HULL AND SIDE HULL POSITION}

(1) longitudinal position

Due to the side hull, the resistance of trimarans become complicated. The relative position of side hull and main hull makes a huge difference on the resistance of trimarans. The wave interference between main hull and side hull has a great impact on resistance of trimarans, if the side body position is appropriate, the resistance of trimarans will be greatly reduced ${ }^{[6][7]}$. Thus this paper identified three different longitudinal space: the middle $(1=0)$, $\operatorname{postmedian}(1=3.175 \mathrm{~m})$ and tail $(l=6.35 \mathrm{~m})$, to study the impact on resistance.

(2) transverse position

Similarly, side hull cannot be too close to main hull, because the cross rolling of main hull will become larger and there 
will be a flow blocking effect; also cannot too big, because that will weaken the interference between side hull and main hull, it is difficult to guarantee the transverse strength and the stability of connecting bridges. This paper identifies four different transverse space b: $3.9 \mathrm{~m}, 4.05 \mathrm{~m}, 4.2 \mathrm{~m}, 4.4 \mathrm{~m}$,to explore the influence of resistance.

\section{NUMERICAL SIMULATION OF RESISTANCE}

\section{STUDY ON SIMULATION METHODS}

The trimaran model can be imported into CFD FINEMarine to do simulation calculation, however, the simulation method must be verified. This paper choose a trimaran with ship model resistance test data, the scale is shown in the table:

Tab. 2 verify the scale of trimaran

\begin{tabular}{c|c|c|c|c|c}
\hline Element & Waterline length $(\mathrm{m})$ & $\begin{array}{c}\text { Modeled breadth } \\
(\mathrm{m})\end{array}$ & Draught $(\mathrm{m})$ & $\begin{array}{c}\text { Displacement } \\
(\mathrm{kg})\end{array}$ & Block coefficient \\
\hline Main hull & 1.94 & 0.4 & 0.11 & 33.1 & 0.436 \\
\hline Side hull & 0.695 & 0.14 & 0.085 & 2.95 & 0.416 \\
\hline
\end{tabular}

The model of the trimaran model as shown in Fig. 3:

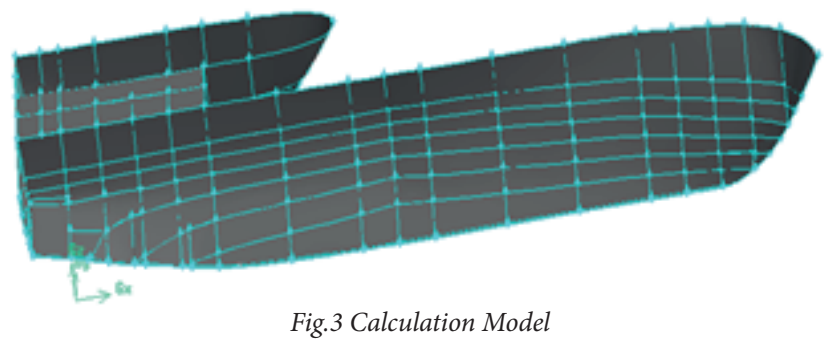

\section{THE COMPUTATIONAL DOMAIN AND MESH}

The selection of computational domain can not only ensure the capture of flow field information, but also reduce the number of grids. Considering the large number of grids required to simulate the flow field, it is difficult to get the required results in a short time. This paper design the ship model with the ratio of 1:10. According to the symmetry of the ship, the ship model was taken half to do the calculation to ensure the results as well as reduce the number of grids. Based on the analysis of the flow field and the references ${ }^{[8][9]}$, the computational domain selected is $10 \mathrm{~L} \times 2 \mathrm{~L} \times 2.5 \mathrm{~L}$, the towing tank entrance from the bow $2 \mathrm{~L}$, depth 1.25L.

The division of the computational domain grid not only have to consider the quality of grid, but also should consider the flow characteristics of the flow field. HEXPRESS adapt hexahedral unstructured mesh grid to divide the whole ship. First step: the initial mesh generation, Second step: the initial mesh refinement. Mesh refinement is only effective to the initial mesh unit near the surface. The initial mesh units which need refinement should be marked, then continuous resolution should be done to the marked mesh units according to specified refinement criterion. Every time do the resolution, mesh units outside the computational domain need to be eliminated. And then figure out whether another resolution is necessary. Eliminate the mesh units which intersect with the surface to form a ladder distribution grid near the surface. The hull geometry file imported into HEXPRESS generate grid as shown in figure 4:

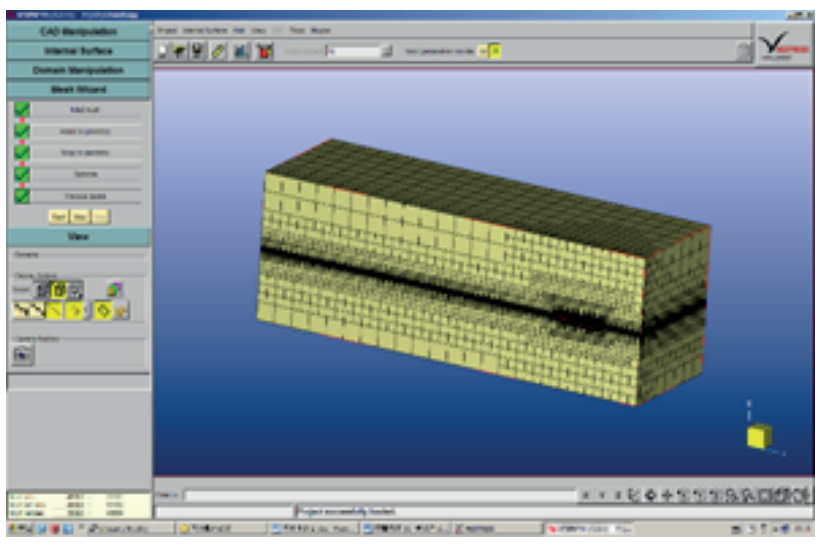

Fig. 4 Mesh

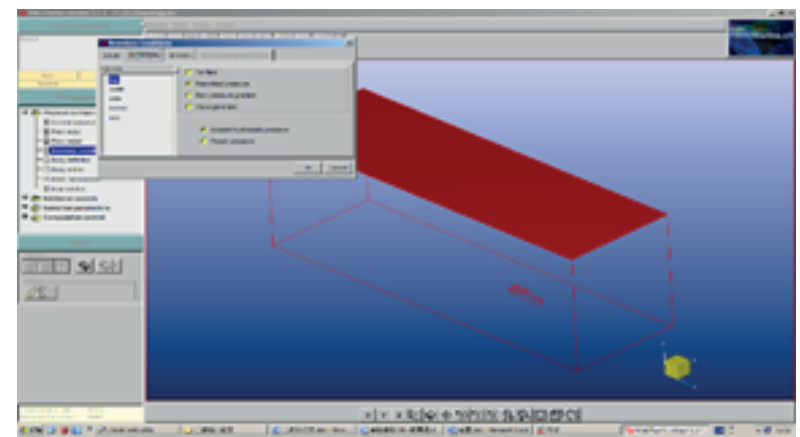

Fig.5 Set grid boundary conditions

\section{BOUNDARY CONDITION}

Save the mesh file and imported it into FINE/Marine to do parameter settings. The calculation parameters mainly include the state parameters, boundary conditions, body definition, body motion parameters, initialization parameters, parameters of controlling calculation and numerical method parameters. The selection of boundary conditions should be consistent with the actual situation, so as to ensure that the numerical simulation is close to the actual. The FINE/Marine boundary condition include three types: solid wall and flow field boundary and the symmetric boundary (Fig. 5). The solid wall boundary condition includes slip wall, nonslip wall and wall function. In this paper, the deck is set to slip wall, the hull surface is set to wall function. FINE/Marine provides four boundary definition for calculation outside the boundary conditions: far field, prescribe pressure, zero pressure gradient and wave generator. The boundary conditions in the calculation area in this paper is: the top and bottom of the computational domain are set to pressure conditions; the 
other direction is set to speed far field boundary. As a result of the calculation by half ship model, so the symmetry plane set for symmetric boundary.

\section{RESULTS}

Using FINE/Marine with the watershed division method and boundary condition definition method, in the scale 1:10, the ship speed is $20 \mathrm{KN}$, the resistance of simulation is $48.36 \mathrm{~N}$, is close to the result of real ship model experiment: $50.17 \mathrm{~N}$. Therefore the method mentioned above can be used to do numerical simulation analysis for trimarans with different characteristic parameters to predict resistance.

\section{THE EFFECT OF DIFFERENT SIDE HULL DISPLACEMENT}

This paper did four sets of numerical simulation calculation with different displacement volume ratio, respectively, using the method mentioned above. The scaling factor is 1:10, the ship speed is $20 \mathrm{KN}$, four schemes of ship model resistance are shown in Table 3:

Tab. 3. four schemes of ship model resistance

\begin{tabular}{c|c|c|c|c}
\hline Scheme & $\begin{array}{c}\text { one } \\
(9 \%)\end{array}$ & two (12\%) & three $(15 \%)$ & four (18\%) \\
\hline resistance (N) & 49.134 & 49.428 & 51.816 & 50.954 \\
\hline
\end{tabular}

Through comparison, it is found that resistance value is small when the side hull displacement volume accounts for $9 \%$ of the total displacement volume. At the same time, the resistance value of the second scheme is close to the resistance value of the first scheme. Therefore, the resistance performance is better when the displacement volume of side hull accounted for $9 \%$ to $12 \%$ of the total displacement volume. The main hull and side hulls can produce favorable interference within the ratio range.

\section{STUDY ON DIFFERENT POSITION OF SIDE HULLS}

Considering the initial metacentric height and stability are affected due to the small side hull in Scheme One, This paper took the Scheme Two: Ratio $12 \%$ to study the impact of different side hull position on the resistance performance. The three longitudinal position: middle, postmedian, tail. The transverse space b value for $3.9 \mathrm{~m}, 4.05 \mathrm{~m}, 4.2 \mathrm{~m}, 4.4 \mathrm{~m}$.

When transverse space $b=4.05 \mathrm{~m}$, The analytical results of CFD numerical simulation are shown in Table 4 with three groups of different longitudinal positions:

Tab. 4. ship model resistance under different longitudinal position

\begin{tabular}{c|c|c|c}
\hline $\begin{array}{c}\text { longitudinal } \\
\text { positions }\end{array}$ & $\begin{array}{c}\text { Middle } \\
(1=0 \mathrm{~m})\end{array}$ & $\begin{array}{c}\text { Postmedian } \\
(1=3.175 \mathrm{~m})\end{array}$ & $\begin{array}{c}\text { Rear } \\
(1=6.35 \mathrm{~m})\end{array}$ \\
\hline $\begin{array}{c}\text { resistance } \\
(\mathrm{N})\end{array}$ & 55.298 & 56.624 & 49.428 \\
\hline
\end{tabular}

Through comparison with the resistance of three groups of different longitudinal positions, It is found that, the value of resistance is minimum when the stern transom plate of side hulls are flush with the stern transom plate of main hull. Four sets of numerical simulation calculation were done with different transverse position, the scaling factor is $1: 10$, the ship speed is $20 \mathrm{KN}$, four schemes of ship model resistance are shown in Table 5:

Tab. 5. ship model resistance under different transverse position

\begin{tabular}{c|c|c|c|c}
\hline $\begin{array}{c}\text { transverse } \\
\text { position }(\mathrm{m})\end{array}$ & 3.9 & 4.05 & 4.2 & 4.4 \\
\hline resistance $(\mathrm{N})$ & 50.886 & 49.428 & 51.632 & 52.610 \\
\hline
\end{tabular}

From four transverse space calculation results showed, with the gradually increase of the transverse space, resistance values decreased at begining and then increased. The resistance value minimum when the transverse space $\mathrm{b}=4.05 \mathrm{~m}$. Therefore the resistance performance is best when transverse space $b=4.05 \mathrm{~m}$.Through comparison, the resistance performance is best when the stern transom plate of side hulls are flush with the stern transom plate of main hull and the transverse space is $101.25 \% \mathrm{~b}$.

\section{THE GENERATION OF RESISTANCE CHART}

Due to the side hull, interference resistance exists between the main hull and the side hull. Up to now, there are no charts nor formulas to estimate the resistance of trimarans. This paper did simulation calculation with combination of the ratio of displacement $9 \%, 12 \%, 15 \%, 18 \%$ and transverse space $\mathrm{b}=97.5 \% \mathrm{~B}, 101.25 \% \mathrm{~B}, 105 \% \mathrm{~B}, 110 \% \mathrm{~B}$ with side hull in middle, postmedian and rear tail. The scaling factor is $1: 10$, Froude number $=0.73$. The resistance chart(Fig.6).

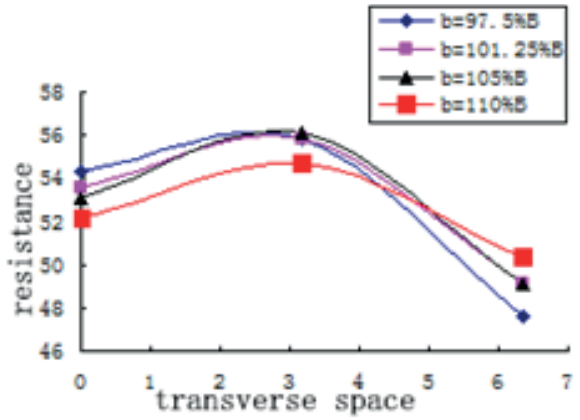

(a)

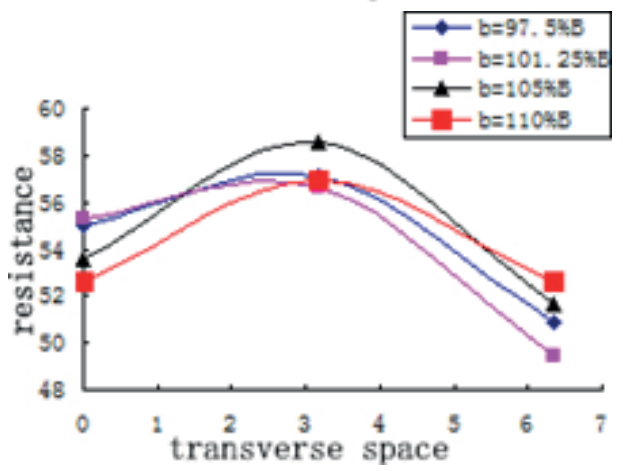

(b) 

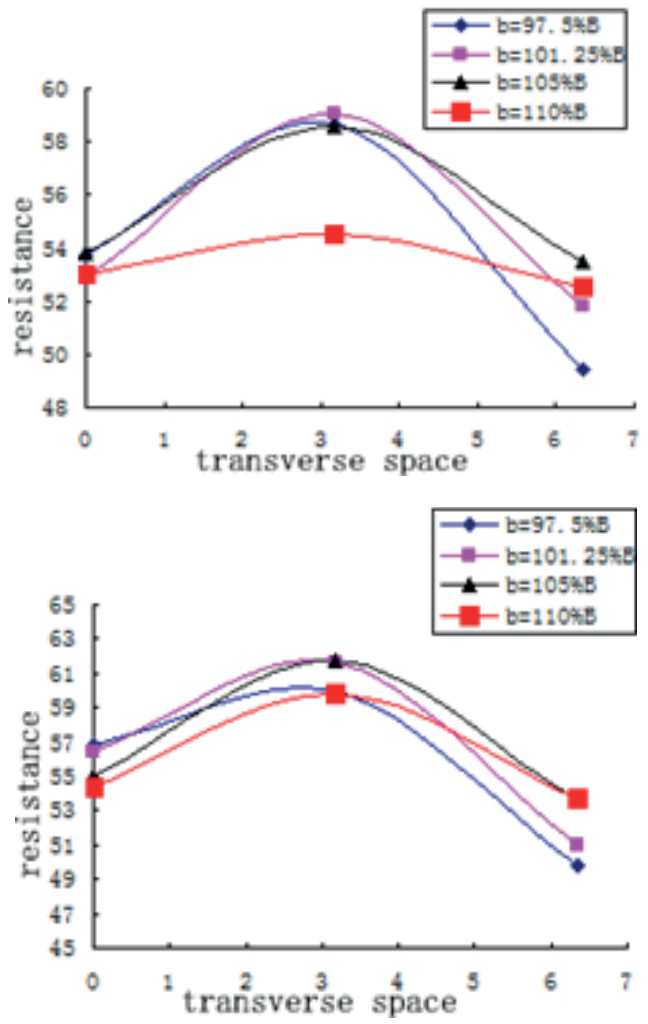

Fig.6. resistance chart: (a) volume ratio 9\%; (b) volume ratio $12 \%$; (c) volume ratio $15 \%$; (d) volume ratio $18 \%$

\section{CONCLUSION}

Operation and maintenance ships are necessary for offshore wind farms. The good performance of ships are very important for completing the operation mission in rough sea conditions. This paper used the ratio of displacement and relative position as characteristic parameters to do numerical simulation analysis, obtained the following conclusions:

(1) when the displacement of side hull is $9 \% \sim 12 \%$ of total displacement, the resistance performance of trimaran is better.

(2) when the stern transom plate of side hulls are flush with the stern transom plate of main hull, transverse space is $101.25 \% \mathrm{~B}$, the resistance performance of trimaran is better.

(3) the numerical simulation method used in this paper is more credible, the resistance chart obtained has reference value in the estimation of trimaran.

\section{REFERENCES}

1. Wang Xianjun [D]. of Harbin Engineering University master's degree thesis of engineering calculation of shallow water body resistance, 2006.3
2. Li Peiyong. Multi hull Ph.D. performance and conceptual design of [D]. dissertation of Shanghai Jiao Tong University, 2002.1

3. Cai Xingong, Wang Ping, Xie Xiaomin. The layout of the resistance calculation and experimental study on [J]. hydrodynamics of trimaran optimization, 2007,22 (2)

4. Wang, Lu Xiaoping, Zhan Jinlin. New progress in the study of water dynamics and ship [J]. trimaran ship mechanics, $2011,15(7)$

5. Jiang Zongyu, Zong Zhi, Jia Jingbei yinglang. Under the condition of the trimaran heave and pitch motion parameters of [J]. Chinese shipbuilding, 2010,51 (4)

6. Zheng Cong Gang, Wang Yaohui. Law, three side optimization design of [J]. ship body position, 2012,23 (4)

7. China Shipbuilding Industry Corporation. Ship design practical manual $[\mathrm{M}]$. National Defence Industry Press, 1998.12

8. Deng Rui, Huang De-bo, Li Jia, Cheng Xuan-Kai, Lei Yu. Discussion of Grid Generation for Catamaran Resistance Calculation[J]. Journal of Marine Science and Application 2010,9:187-191.

9. Xie Yunping, Yao Weiet al. Study on numerical simulation method of wave resistance of high speed ships with numerical wave tanks [J]. ship engineering, 2013, 35 (2). 